David Last

Françoise Peyrin

Geneviève Guillot

\section{Accuracy of 3D MR microscopy for trabecular bone assessment: a comparative study on calcaneus samples using 3D synchrotron radiation microtomography}

Published online: 15 March 2005

(C) ESMRMB 2005

The online version of the original can be found at

http://dx.doi.org 10.1007/s10334-004-0075-3

D. Last · G. Guillot (®)

U2R2M CNRS UMR8081, Bât. 220,

Université Paris-Sud, 91405 Orsay Cedex, France

E-mail: guillot@u2r2m.u-psud.fr

Tel.: +33-1-69-156746

Fax: +33-1-69-154136

F. Peyrin

CREATIS, UMR CNRS 5515

INSA, 69621 Villeurbanne Cedex,

France

F. Peyrin

ESRF, BP 200,

38043Grenoble Cedex, France

\section{MAGMA (2005) 18: 25-33}

Figure 1 was incorrect as published.

The figure should be as follows:

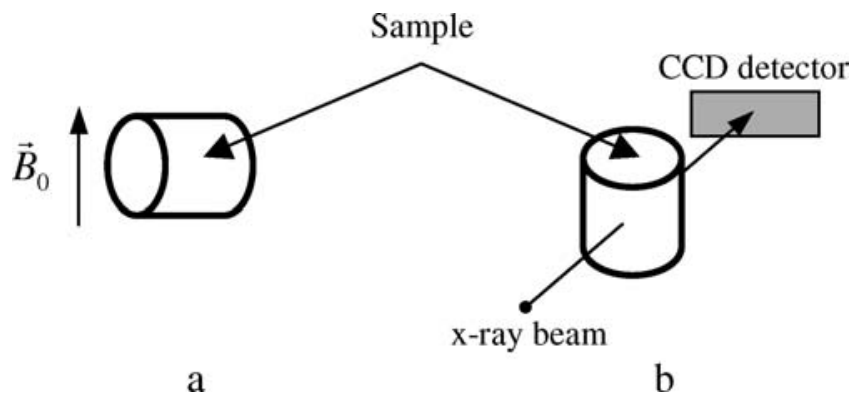

Fig. 1 Schematics of the sample orientation relative to the magnetic field $\vec{B}_{0}$ (a), and to the synchrotron $\mathrm{x}$-ray beam (b) 